\title{
Metabolic Analysis in Women with Polycystic Ovary Highlight Specific Biomarkers of Insulin Resistance
}

\author{
CAMELIA LARISA VONICA ${ }^{1}$, ADRIANA FODOR ${ }^{1,3}$, GABRIELA ROMAN ${ }^{1,3}$, ANDRADA ALINA MUREASAN $^{1}$, \\ ANCA DANIELA FARCAS ${ }^{2,4 *}$,GEORGETA VICTORIA INCEU ${ }^{1}$, ADRIANA RUSU ${ }^{1}$, CARMEN EMANUELA GEORGESCU ${ }^{1,5}$ \\ II Iuliu Hatieganu University of Medicine and Pharmacy, $6^{\text {th }}$ Department of Medical Specialities, 8 Victor Babes Str., 400012, \\ Cluj Napoca, Romania \\ ${ }^{2}$ Iuliu Hatieganu University of Medicine and Pharmacy, $5^{\text {th }}$ Department of Internal Medicine, 8 Victor Babes Str., 400012 , \\ Cluj Napoca, Romania \\ ${ }^{3}$ Emergency County Hospital, Diabetes, Nutrition and Metabolic Diseases Clinic, 3-5 Clinicilor Str, 400006, Cluj Napoca, Romania \\ ${ }^{4}$ Emergency County Hospital, Cardiology Department, 3-5 Clinicilor Str, 400006, Cluj Napoca, Romania \\ ${ }^{5}$ Emergency County Hospital, Endocrinology, 3-5 Clinic, Clinicilor Str, 400006, Cluj Napoca, Romania
}

\begin{abstract}
The aim of the paper is to detect insulin resistance (IR) biomarkers via metabolomics. It is important to understand the PCOS pathophysiology, diagnosis measures and, subsequently, to improve treatment type and time of IR in PCOS. In most cases, almost half of the women with PCOS have IR which is triggered by inflammation, glucotoxicity and lipotoxicity. In this work was conducted a systematic review of all the papers that used metabolomics for detecting IR biomarkers in PCOS women. The exclusion criteria were: reviews, study population with women bellow 18 years of age, studies including animals and articles not in English, remaining 4 records. The results from the literature shown that phosphatidylcholines were decreased in IR PCOS women when compared to controls. Nonetheless, trans-2-hexenoylcoa, linoleic acid, leucine, myristic acid and palmitic acid regarding lipid metabolism and tyrosine, lysine, phenylalanine $\alpha$-aminoadipic acid regarding amino acid metabolism were also corelated to IR in PCOS women when compared with healthy or IR controls. Lactate was the only increased metabolite related to glucose metabolism in IR PCOS women. Metabolic alteration in PCOS women with IR when are compared with controls and results that those are brought by both PCOS and IR. Lyso-phosphatidylcholine have an important pro-inflammatory and altered insulin signaling effect, both alterations being considered hallmarks of PCOS women. Serine hyperphosphorylation of the receptor accentuates IR by decreasing the signaling of insulin receptor. Moreover, high levels of lactate correlated with IR in PCOS women may indicate high muscle glycolysis, hepatic glucose production and peripheral glucose uptake. IR biomarkers in PCOS women were evidenced by metabolomics technique.
\end{abstract}

Keywords: Polycystic ovary syndrome, insulin resistance, metabolomics, women, plasma, metabolism, biomarkers.

Polycystic ovary syndrome (PCOS) is considered a most frequent endocrine pathology, highly heterogeneous, of women at the childbearing age. Last decades have focused on defining clinical and biochemical characteristics of this syndrome, and also pathophysiological mechanisms and possible causes [1-3]. This syndrome is later diagnosed than its debut. Many women refer to an endocrinologist or gynecologist when they trying to conceive and not succeed. In this case, after pharmacological treatment fails, they try invasive procedures and even in vitro fertilization $[4,5]$. Nonetheless, important steps were made regarding the impact of metabolic comorbidities in PCOS women. Between those factors, insulin resistance (IR) and obesity have been linked to the pathogenesis of PCOS, and to the susceptibility of developing early impaired glucose tolerance and cardio-vascular diseases [6]. The metabolic incapacity to adapt to energy requirements or substrate streams leads over time, to organ dysfunction and eventually disease [7].

The omic techniques (Figure 1) have identified various pathways and disease biomarkers in chronic metabolic pathologies like type 2 diabetes mellitus (DM2), IR, dyslipidemia and obesity [8-10].

of these techniques, metabolomics has recently emerged, being used in small groups also in PCOS women.
The biomarkers associated with chronic metabolic diseases in terms of branched-chain amino acid catabolism (BCAA), lipid and glucose metabolism [11]. The existing metabolomic studies, which are focused on the study of PCOS, all suggest metabolic alterations regarding carbohydrates, proteins and lipids, all of these are tangled to energy metabolic pathways [12]. Thus, not all studies have focused their attention to eliminate the influence of obesity or insulin resistance in their different stages.

Given the strong association of IR with chronic anovulation in PCOS and all the metabolic diseases previously mentioned, all of these are not a consistent diagnostic criterion. In most cases IR is associated with PCOS, independently of obesity and age. Nonetheless, IR is yet scarcely investigated in the absence of impaired glucose tolerance, or in the case of lean PCOS pathology [13]. Consequently, IR assessment in lean PCOS pathology could be underestimated due to the absence of obesity.

Hence, the detection of plasma biomarkers which influence insulin signaling, is important for clinical diagnosis a better perception of the mechanisms leading to IR and, better IR treatment for women with PCOS. We have focused the study on metabolomic biomarkers that could define a specific metabolic fingerprint to distinguish between PCOS women with and without IR.

\footnotetext{
*email: ancafarcas@yahoo.com, Phone: +40 744780873
} 


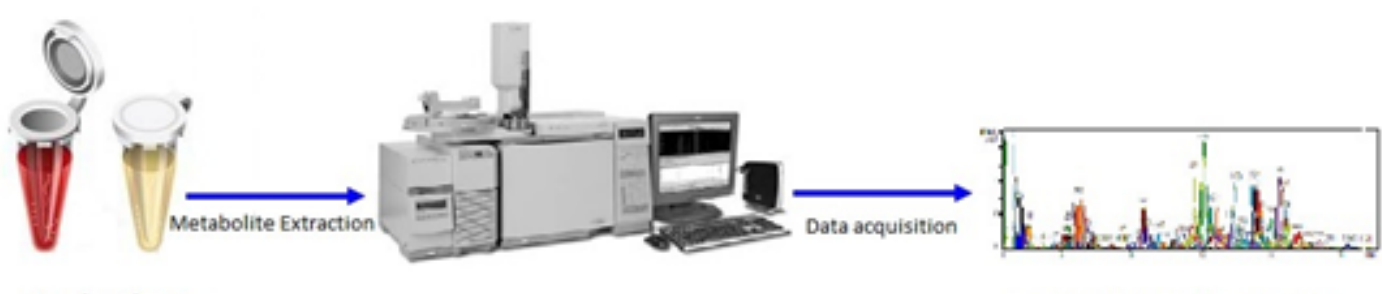

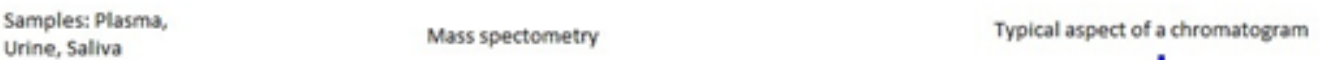

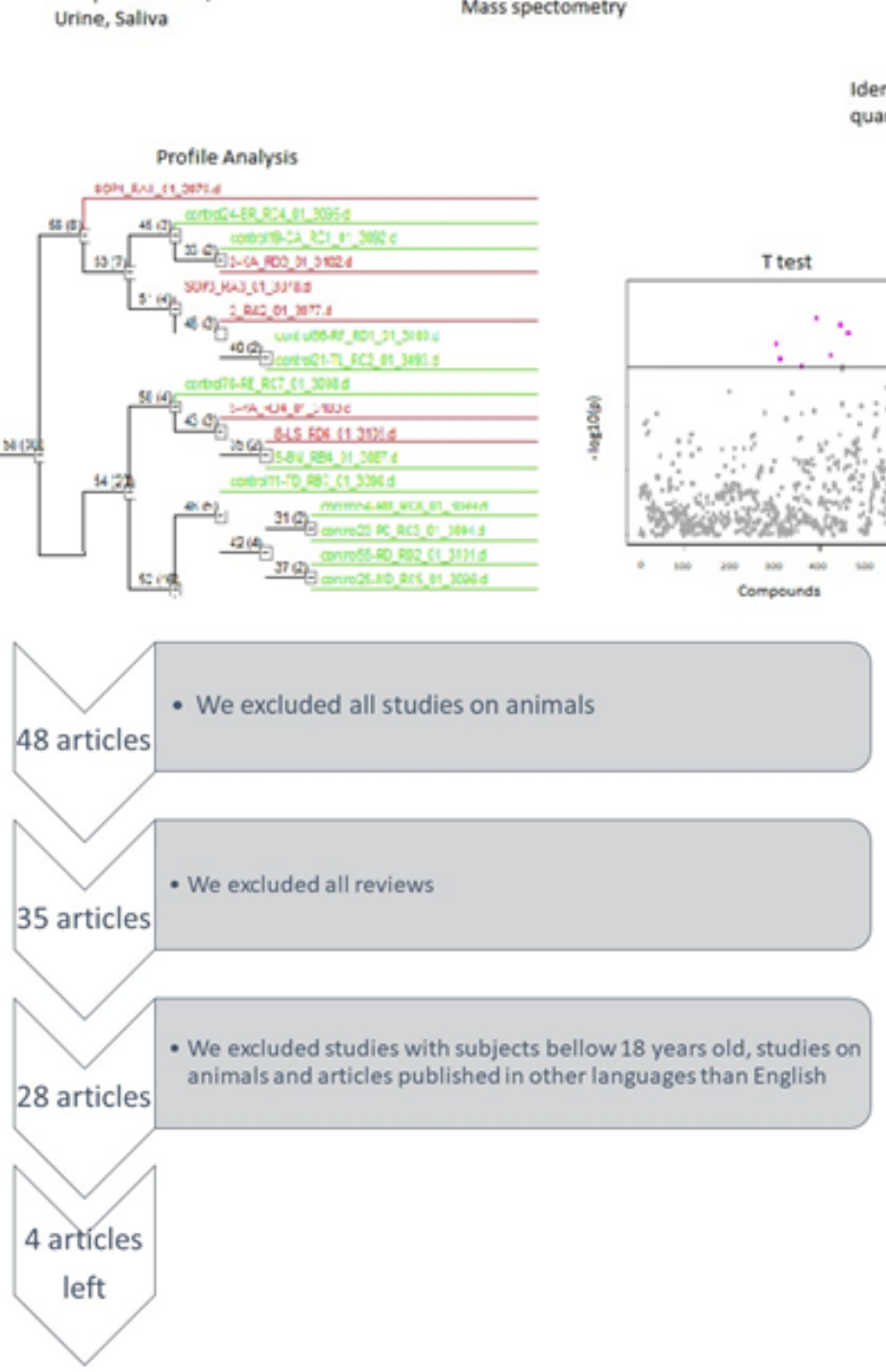

\section{Experimental part}

Material and methods

Using the standard methods of Cochrane, we have operated a complete search of the medical data bases including: International Clinical Trials Registry Platform, the Cochrane Central Register of Controlled Trials in the Cochrane Library; MEDLINE via PubMed, ClinicalTrials.gov; using the Medical Subject Headings search terms: polycystic ovary syndrome and metabolomics, respectively. Our search yielded 48 articles. Each article was evaluated independently by two reviewers, which had excluded all the studies which did not define IR, in the enrolled participants by one of the followings: HOMA-IR or euglycaemic clamp. Most of the studies did not separate the subgroups of PCOS women with IR and, consequently, they did not compare them with non-IR PCOS women or controls. Also, we excluded all the reviews, studies with patients bellow 18 years of age or on animals and articles published in other languages than English. Finally, the refined search lead to 4 articles. The selection of the articles is presented in Figure 2.
Data was collected after being carefully analyzed by the authors. The following characteristics were considered: number of participants, control group characteristics, study design, PCOS diagnostic method used, inclusion/exclusion criteria, metabolomic technique used, sample used for metabolomics, the metabolites identified to have been altered in IR PCOS patients compared to either non-IR PCOS or controls. Data summarizing is presented in Tables 1 and 2)

\section{Results and discussions}

Anthropometric data and age of patients with PCOS women included in the studies were:

- body mass index $\left(\mathrm{kg} / \mathrm{m}^{2}\right)$ was $19.89 \pm 1.81$ [14] $22.7 \pm 5.3[15], 24.29 \pm 0.46[16]$ and 34.6 \pm 5.1 [17]

- aged (years) was 24.36 \pm 4.18 [14], 28.5 \pm 3.5 [15], $28 \pm 0.59$ [16] and $37 \pm 6$ [17].

Creatine, serine, lactate, glycine, dodecanedioic acid and threonine were glucose metabolism related metabolites found decreased in IR PCOS compared with controls or non-IR PCOS women [14-17]. Although, lactate was also found increased in IR PCOS women comparatively with non-IR PCOS patients [16]. 
Table 1

METABOLITES IDENTIFIED WHEN COMPARING IR PCOS WOMEN WITH NON-IR PCOS WOMEN OR HEALTHY CONTROLS

\begin{tabular}{|c|c|c|c|}
\hline Authors & Pathway & Metabolite & Trend \\
\hline \multirow{4}{*}{$\begin{array}{l}\text { Chang et al. (2017) } \\
\text { Obese PCOS vs. obese } \\
\text { controls with MetS }\end{array}$} & Amino acid metabolism & Lysine & $\uparrow$ \\
\hline & Amino acid metabolism & $\alpha$-aminoadipic acid & $\uparrow$ \\
\hline & Aromatic amino acids metabolism & Tyrosine + Phenilalanine & $\uparrow$ \\
\hline & Lipid metabolism & Linoleic acid & $\uparrow$ \\
\hline \multirow{11}{*}{$\begin{array}{l}\text { Chen et al. (2016) } \\
\text { IR PCOS vs non-IR } \\
\text { PCOS }\end{array}$} & Lipid metabolism & PC (38:4) & $\downarrow$ \\
\hline & Lipid metabolism & $\mathrm{PC}(34: 2)$ & $\downarrow$ \\
\hline & Lipid metabolism & $\mathrm{PC}(36: 2)$ & $\downarrow$ \\
\hline & Lipid metabolism & $\mathrm{PC}(36: 2)$ & $\downarrow$ \\
\hline & Lipid metabolism & PE (38:4) & $\downarrow$ \\
\hline & Lipid metabolism & $\mathrm{PC}(38: 3)$ & $\downarrow$ \\
\hline & Lipid metabolism & $\mathrm{PC}(38: 4)$ & $\downarrow$ \\
\hline & Lipid metabolism & PC (40:5) & $\uparrow$ \\
\hline & Lipid metabolism & Trans-2-Hexenoyl-CoA & $\uparrow$ \\
\hline & Lipid metabolism & Palmitic acid & $\downarrow$ \\
\hline & Lipid metabolism & LysoPC (18:2) & $\downarrow$ \\
\hline \multirow{7}{*}{$\begin{array}{l}\text { Chen et al. (2016) } \\
\text { IR PCOS vs Control }\end{array}$} & Lipid metabolism & LysoPC (18:2) & $\downarrow$ \\
\hline & Lipid metabolism & PC (34:2) & $\downarrow$ \\
\hline & Lipid metabolism & $\mathrm{PC}(36: 4)$ & $\downarrow$ \\
\hline & Lipid metabolism & $\mathrm{PC}(36: 2)$ & $\downarrow$ \\
\hline & & Tri lauric glyceride & $\uparrow$ \\
\hline & Lipid metabolism & $\mathrm{PC}(38: 3)$ & $\downarrow$ \\
\hline & Lipid metabolism & $\mathrm{PC}(38: 4)$ & $\downarrow$ \\
\hline \multirow{9}{*}{$\begin{array}{l}\text { Dong et al. } 2015 \text { IR } \\
\text { PCOS vs non-IR PCOS }\end{array}$} & Lipid metabolism & Linoleic acid & $\uparrow$ \\
\hline & Lipid metabolism & Myristic acid & $\uparrow$ \\
\hline & Lipid metabolism & Palmitoleic acid & $\uparrow$ \\
\hline & Lipid metabolism & Vaccenic acid & $\uparrow$ \\
\hline & Amino acid metabolism & 5-Methoxysalicylic-acid & $\downarrow$ \\
\hline & Carbohydrate metabolism & Creatine & $\downarrow$ \\
\hline & Amino acid metabolism & Arginine-succinic acid & $\downarrow$ \\
\hline & Carbohydrate metabolism & Dodecanedioic acid & $\downarrow$ \\
\hline & Amino acid metabolism & Indoxyl sulfate & $\downarrow$ \\
\hline \multirow{5}{*}{$\begin{array}{l}\text { Zhao et al. } 2012 \text { PCOS } \\
\text { women vs. healthy } \\
\text { controls }\end{array}$} & Carbohydrate metabolism & Lactate & $\uparrow$ \\
\hline & $\begin{array}{l}\text { Branched chain amino acids metabo- } \\
\text { lism }\end{array}$ & Leucine & $\uparrow$ \\
\hline & Carbohydrate metabolism & Glycine & $\downarrow$ \\
\hline & Carbohydrate metabolism & Serine & $\downarrow$ \\
\hline & Carbohydrate metabolism & Threonine & $\downarrow$ \\
\hline
\end{tabular}

Table legend: PCOS- polycystic ovary syndrome; IR- insulin resistant; LysoPC - lysophosphatidylcholine; PC phosphatidylcholine, MetS-metabolic syndrome.

However, lysine, leucine, tyrosine, $\alpha$-aminoadipic acid and phenylalanine were the amino acid metabolism related metabolites, correlated to IR PCOS women compared with control/ non-IR PCOS women. Nonetheless, arginine succinic acid, 5-methoxysalicylic-acid and indoxyl sulfate were reported as decreased in IR PCOS women [14-17].

Also, various phosphatidylcholines are described as being decreased in IR PCOS women, compared to controls. However, phosphatidylcholine (40:5) was the only phosphatidylcholine lipid metabolite increased in IR PCOS women.
Other metabolites corelated to IR PCOS women were linoleic acid, vaccenic acid, palmitic acid, trans-2hexenoyl-coa, myristic acid. Only lyso - phosphatidylcholine and palmitic acid are invers proportional correlated to IR of PCOS women [14-17].

\section{Metabolites Related to Glucose Metabolism}

A specific characteristic of PCOS, independent of obesity, is IR and increased gluconeogenesis [18]. Latest researches regarding the metabolites related to glucose 


\begin{tabular}{|c|c|c|c|c|c|}
\hline \multirow{2}{*}{ Study } & Population & \multirow{2}{*}{$\begin{array}{l}\text { Type of metabo- } \\
\text { lomics }\end{array}$} & \multicolumn{2}{|r|}{ Selection criteria } & \multirow{6}{*}{$\begin{array}{c}\text { Table } 2 \\
\text { CHARACTERISTICS } \\
\text { OF INCLUDED } \\
\text { STUDIES }\end{array}$} \\
\hline & $N$ & & Inclusion & Exclusion & \\
\hline $\begin{array}{l}\text { Chang et al. } \\
\text { (2017) }\end{array}$ & $\begin{array}{l}\text { - } 20 \text { obese PCOS } \\
\text { - } 18 \text { obese controls }\end{array}$ & LC TOF-MS & \multirow{4}{*}{$\begin{array}{l}\text { Rotterdam } \\
\text { criteria for } \\
\text { PCOS diagno- } \\
\text { sis }\end{array}$} & $\begin{array}{l}\text { DM2, hypertension, medication for } \\
\text { PCOS or hypertension, smokers }\end{array}$ & \\
\hline $\begin{array}{l}\text { Chen et al. } \\
\text { (2016) }\end{array}$ & $\begin{array}{l}\text { - } 21 \text { PCOS with IR, } \\
\text { - } 19 \text { PCOS without } \\
\text { IR } \\
\text { - } 59 \text { healthy controls }\end{array}$ & UHPLC/Q-TOFMS & & $\begin{array}{l}\text { age }<20 \text { or }>40 \text { years; pregnancy, } \\
\text { delivery or miscarriage in the previ- } \\
\text { ous } 3 \text { months; other hyperandrogenic } \\
\text { diseases, cardiovascular diseases, } \\
\text { steroid therapy. }\end{array}$ & \\
\hline $\begin{array}{l}\text { Dong et al. } \\
\text { (2015) }\end{array}$ & $\begin{array}{l}\text { - } 11 \text { non-IR PCOS, } \\
\text { - } 9 \text { PCOS with IR } \\
\text { - } 15 \text { healthy controls }\end{array}$ & UHPLC/Q-TOFMS & & $\begin{array}{l}\text { other hyperandrogenic diseases, } \\
\text { Cushing's syndrome, thyroid disease, } \\
\text { hyperprolactinemia, DM2 }\end{array}$ & \\
\hline $\begin{array}{l}\text { Zhao Y. et al } \\
\text { (2012) }\end{array}$ & $\begin{array}{l}\text { - } 217 \text { PCOS } \\
\text { - } 48 \text { women similar } \\
\text { age }\end{array}$ & $\begin{array}{l}\text { 1H NMR and } \\
\text { GC/TOF-MS }\end{array}$ & & $\begin{array}{l}\text { other hyperandrogenic diseases, } \\
\text { Cushing's syndrome, thyroid dys- } \\
\text { function, hyperprolactinemia, DM2 } \\
\text { and cardiovascular disease }\end{array}$ & \\
\hline
\end{tabular}

Table legend: PCOS- polycystic ovary syndrome; BMI- body mass index; LC TOF-MS - liquid chromatography/time-offlight mass spectrometry; UPLC-MS/MS - ultra-performance liquid chromatography coupled with mass spectrometry; $1 \mathrm{H}$ NMR-1H nuclear magnetic resonance; GC/TOF-MS - gas chromatography/time-of-flight mass spectrometry; Q-TOF MSquadrupole time-of-flight mass spectrometry. All the studies used plasma for metabolite determination. The study design for the papers included was case control.

metabolism had evidenced lactate, dodecanedioic acid and citric acid atPCOS women [13-16,17]. According with these, it was reported that lactate plasma levels were associated with IR, and not with obesity [16]. Although, lactate levels where previously reported to be linked to obesity and adipose mass in women without PCOS [19]. Glucose generation for energetic substrate is initiated by lactate and gluconeogenic amino acids. The first three major sources of lactate are: subcutaneous adipose tissue, skeletal muscles and the brain [20]. Consequently, increased levels of lactate in PCOS women may indicate alterations in muscle glycolysis, glucose liver metabolism and peripheral glucose uptake.

\section{Metabolites Related to Lipid Metabolism}

In terms of lipid metabolism, PCOS is known to be characterized by atherogenic dyslipidemia with increased low-density and very-low density lipoprotein cholesterol and decreased high density lipoproteins [16,21]. Moreover, fatty acids oxidation, considered an important energy source, in PCOS has been reported as decreased. This leads to fatty acids accumulation and, consequently, lipotoxicity and non-alcoholic fatty liver disease. Nonetheless, lipotoxicity modulates insulin sensitivity, inducing impaired glucose metabolism and eventually DM2 in PCOS [22]. Dong et al [14] has reported altered lipid metabolism in IR PCOS subgroup, suggesting that this subgroup might be more predisposed to develop DM2 than non-IR PCOS women.

Lipid metabolites identified as being linked to IR in PCOS comparatively with non-IR patients were linoleic acid, palmitoleic acid, vaccenic acid and myristic acid [14, 17]. In contrast, a study including 8 European countries has developed a FA-pattern score that evaluates the risk of developing DM2. This pattern has high linoleic acid concentration as being associated with a lower incidence of DM2 [23]. Although, this FA pattern score diminishes the linoleic acid capability to distinguish between IR and
non-IR PCOS women, none of the participants enrolled in this study had PCOS and this may had influenced the results. Additionally, the differences could be explained by other factors that may influence linoleic acid levels like diet, metabolism and genetics.

Metformin treatment for the reduction IR in obese PCOS patients with infertility PCOS improves ovulation, suggesting that IR impairs 0ocyte development [24]. Also, IR stimulates ovarian androgen secretion accentuating hyperandrogenism phenotype in PCOS women [24,25]. In general, all treatments that target IR lowering, including diet, weight loss or pharmacological treatment, improve reproductive function and pregnancy rates. Also, high levels of FA are linked to increased lipolysis suggesting not just central IR, but also IR in the adipose tissue [26].

Other metabolites related to lipid metabolism were reported by Chen et al [15]. Five phosphatidylcholines (PCs) and lyso-phosphatidylcholine (LysoPC) (18:2) were reported as being decreased and trilauric glyceride was increased in the plasma samples of IR PCOS patients compared to healthy controls and non-IR PCOS. The metabolic alterations seen when were compared IR PCOS samples with healthy controls samples, are brought by the cumulative effects of both PCOS and IR. Lyso PC has an important role in PCOS IR due to its pro-inflammatory character and altered insulin signaling effect. A particular interest, of all the lipid biomarkers identified by Chen et al [15], decanoylcarnitine and trilauric glyceride showed the highest sensitivity and specificity when it comes to distinguish between IR PCOS and non-IR PCOS.

\section{Metabolites Related to Amino Acid Metabolism}

Metabolomics technique has demonstrated that branched-chain amino acid (BCAAs) are associated to IR in women with PCOS when is compared to non-IR PCOS or healthy controls [14-17]. Considered to be strong biomarkers, BCAA were associated with IR even after adjusting the results for ethnicity, sex, genetics, and dietary pattern. Consequently, they may be used as early 
biomarkers of IR, predicting early risk for impaired glucose tolerance and DM2 [1].

The proteinogenic BCAAs associated with IR in women with PCOS are leucine, isoleucine and valine. Previous studies have linked high levels of BCAAs obesity IR, suggesting that $B C A A s$ may contribute to the pathogenesis of these metabolic diseases [27,28]. Also, BCAA-restricted diets improve glucose tolerance [29], restores insulin sensitivity and promotes normal weight to obese mice [30,31]. Thus, increased levels of leucine, lysine, isoleucine and valine, phenylalanine and tyrosine were reported in IR PCOS patients [16]. Furthermore, the differences between the groups remained significant after refining results after age, physical fitness, total and visceral adipose mass [32]. Lysine and $\alpha$-aminoadipic acid ( $\alpha$-aa) were associated with HOMA-IR when comparing IR PCOS women with obese controls with metabolic syndrome [17]. Nevertheless, this is consistent with a previous study, which showed that lysine levels are significantly improved after metformin and pioglitazone treatment in PCOS women. [33].

Nonetheless, Zhao et al reported that serine, glycine and threonine were decreased in IR PCOS women. However, women with PCOS have low signaling of insulin receptors caused by serine hyperphosphorylation of receptor and IRS1. Synthesized from serine and threonine, the serine/ threonine phosphatase protein, was involved in regulating glucose and lipid metabolism, but also in insulin action [34]. Therefore, the decreasing of serine and threonine levels, which are substrates used to synthetize serine/ threonine phosphatase protein, were associated with IR in PCOS women [16]. Additionally, a recent review showed that glycine is inversely associated with impaired glucose tolerance and DM2 [35].

\section{Conclusions}

Well-known for its heterogeneity, PCOS has been shown to have different altered pathways including glucose, amino acid and lipid metabolism. In this study, we highlighted the metabolites that characterize IR in PCOS.

Metabolomics fingerprints can be used for understanding the pathophysiology of various diseases. This new omic tool highlighted possible hepatic changes in IR PCOS in terms of gluconeogenesis and lipid metabolism. Lysophosphatidylcholine have an important proinflammatory character and altered insulin signaling effect, both alterations being considered hallmarks of PCOS women. Serine hyper-phosphorylation of the receptor accentuates IR by decreasing the signaling of insulin receptor.

Moreover, high levels of lactate correlated with IR PCOS women may indicate high muscle glycolisis, hepatic glucose production and peripheral glucose uptake. Also, metabolic changes of amino acids concern different BCAAs.

In conclusion, future studies should focus on selecting larger populations with PCOS in order to identify reliable biomarkers for diagnosis, risk estimation and treatment evaluation.

\section{References}

1.CONWAY,G., DEWAILLY, D., DIAMANTI-KANDARAKIS, E. E., ESCOBAR-MORREALE, H.F., FRANKS, S., GAMBINERI A et al. European Journal of Endocrinology.2014; 4: 1-29.

2.COCOLOS, A.M., DUMITRU, N., PETROVA, E.N., COCOLOS, I., TIGLIS, M., DRAGOMIRESCU, R.F.I. et al. Rev. Chim. (Bucharest), 69, no.1, 2018, p. 366-371

3.ANDRESE, E., VATA, D., PORUMB, V., MARTU, C., STATESCU, L., SOLOVASTRU, L.G.,Rev. Chim. (Bucharest), 67, no. 8, 2016, p. 15911593

3648
4.PACU I, IONESCU, C., VLADAREANU, V., BANACU, M., NEACSU, A., CALIN, A.,Rev. Chim. (Bucharest), 68 , no. 5, 2017, p. 1118-1121 5.STELEA, L., PETRE, I., CRAINA, M., VLAICU, B., SISU, A., POP, E., MOLERIU, R.D. ET AL.Rev. Chim. (Bucharest), 69, no. 7, 2018, p. 1842-1845

6.SONG, D.K., HONG, Y.S., SUNG, Y.A., LEE, H. ed. PLOS ONE. 2017;12[5]:e0178120.

7.FARCAS, A.D., VONICA, C.L., GOLEA, A.C. Med Ultrason. 2017; 19(3): 265-271

8.BHATTACHARYA, S., GRANGER, C.B., CRAIG, D., HAYNES, C., BAIN, J., STEVENS, R.D., HAUSER, E.R., NEWGARD, C.B., KRAUS, W.E., NEWBY, L.K., SHAH, S.H. Atherosclerosis. 2014; 232:191-196.

9.MARSO, S.P., DANIELS, G.H., BROWN-FRANDSEN, K., KRISTENSEN, P., MANN, J.F., NAUCK, M.A., NISSEN, S.E., POCOCK, S., POULTER, N.R., RAVN, L.S., ET AL. New Engl J Med. 2016;375:311-322.

10.NEWGARD C. B. (2016). Cell metabolism, 25(1), 43-56.

11.MERINO, J., UDLER, M.S., LEONG, A., MEIGS, J.B. Curr Diab Rep. 2017 Nov 4; 17[12]:135.

12.MURRI, M., INSENSER, M., ESCOBAR-MORREALE, H.F. Clin Chim Acta. 2014 Feb 15; 429:181-8.

13.GONZALEZ, F. Steroids 77 (2012) 300-305.

14.DONG, F., DENG, D., CHEN, H., CHENG, W., LI, Q., LUO, R., ET AL. Anal Bioanal Chem. 2015 J un;407[16]:4683-95.

15.CHEN, Y.X., ZHANG, X.J ., HUANG, J., ZHOU, S.J ., LIU, F., JIANG, L.L., CHEN, M., WAN, J.B., YANG, D.Z. J Pharm Biomed Anal. 2016 Mar 20; 121:141-150.

16.ZHAO, Y., FU, L., LI, R., WANG, L.N., YANG, Y., LIU, N.N. BMC Med. 2012 Nov 30;10:153.

17.CHANG, A.Y., LALIA, A.Z., JENKINS, G.D., DUTTA, T., CARTER, E. ET AL. Metabolism. 2017 J un; 71:52-63.

18.OMABE, M., OMABE, K.N., CLEMENT, F.A., OMABE, G.M., Endocr. Metab. Immune Disord. Drug Targets, 2016, 16(1), 61-71

19.XIE, B., WATERS, M.J., SCHIRRA, H.J ., J Biomed Biotechnol 2012:805683.

20.KREISBERG, R. A., New England J ournal of Medicine, 1972; vol. 287, no. 3, 132-137

21.SUN, L., HU, W., LIU, Q., HAO, Q., SUN, B., ZHANG, Q. ET AL. J Proteome Res. 2012 May 4;11[5]:2937-46.

22.CONDORELLI, R.A., CALOGERO, A.E., DI MAURO, M., MONGIOI, L.M., CANNARELLA, R., ROSTA, G. ET AL. J Endocrinol Invest. 2017 Sep 23.

23.IMAMURA, F., SHARP, S.J., KOULMAN, A., ET AL, PLoS Medicine. 2017;14[10]:e1002409.

24.CHAVARRO, J.E., EHRLICH, S., COLACI, D.S., WRIGHT, D.L., TOTH, T.L., PETROZZA, J.C., ET AL. 2012;98:109-16.

25.ADASHI, E.Y., HSUEH, A.J ., YEN, S.S. Endocrinology. 1981; 108:14419.

26.ROSENFIELD, R.L., BARNES, R.B., CARA, J.F., LUCKY, A.W., Fertility and sterility. 1990; 53:785-91.

27.LYNCH, C.J., ADAMS, S.H., Nature Reviews. Endocrinology. 10 (12): 723-36.

28.NEW GARD, C.B., AN, J., BAIN, J .R., MUEHLBAUER, M.J., STEVENS, R.D., LIEN, L.F., HAQQ, A.M., SHAH, S.H., ET AL. Cell Metabolism.2013; 9 (4): 311-26.

29.FONTANA, L., CUMMINGS, N.E., ARRIOLA APELO, S.I., NEUMAN, J.C., KASZA, I., SCHMIDT, B.A. ET AL,. Cell Reports. 2016; 16 (2): $520-530$.

30.CUMMINGS, N.E., WILLIAMS, E.M., KASZA, I., KONON, E.N., SCHAID, M.D., SCHMIDT, B.A., POUDEL, C. ET AL. The Journal of Physiology 2018 Feb 15;596(4):623-645..

31.WHITE, P.) ., LAPW ORTH, A.L., AN, I., WANG, L., MCGARRAH, R.W., STEVENS, R.D., ILKAYEVA, O., GEORGE, T., ET AL, Molecular Metabolism 2016 Apr 22;5(7):538-551.

32.WIKLUND, P., ZHANG, X., PEKKALA, S., AUTIO, R., KONG, L. ET AL. Sci Rep, 2016 Apr 15;6:24540.

33.IRVING, B.A., CARTER, R.E., SOOP, M., WEYMILLER, A., SYED, H., KARAKELIDES, H., ET AL. Metabolism. 2015 J un;64[6]:720-8.

34.BOUCHER, J., KLEINRIDDERS, A., KAHN, C.R., Cold Spring Harbor Perspectives in Biology. 2014;6[1]:a009191.

35.GUASCH-FERRE, M., HRUBY, A., TOLEDO, E., ET AL. Diabetes Care. 2016;39[5]:833-846

Manuscript received: 25.02 .2019 